\title{
STRATEGI PROGRAMMING TELEVISI SWASTA DALAM PROGRAM TAYANGAN PRIME TIME
}

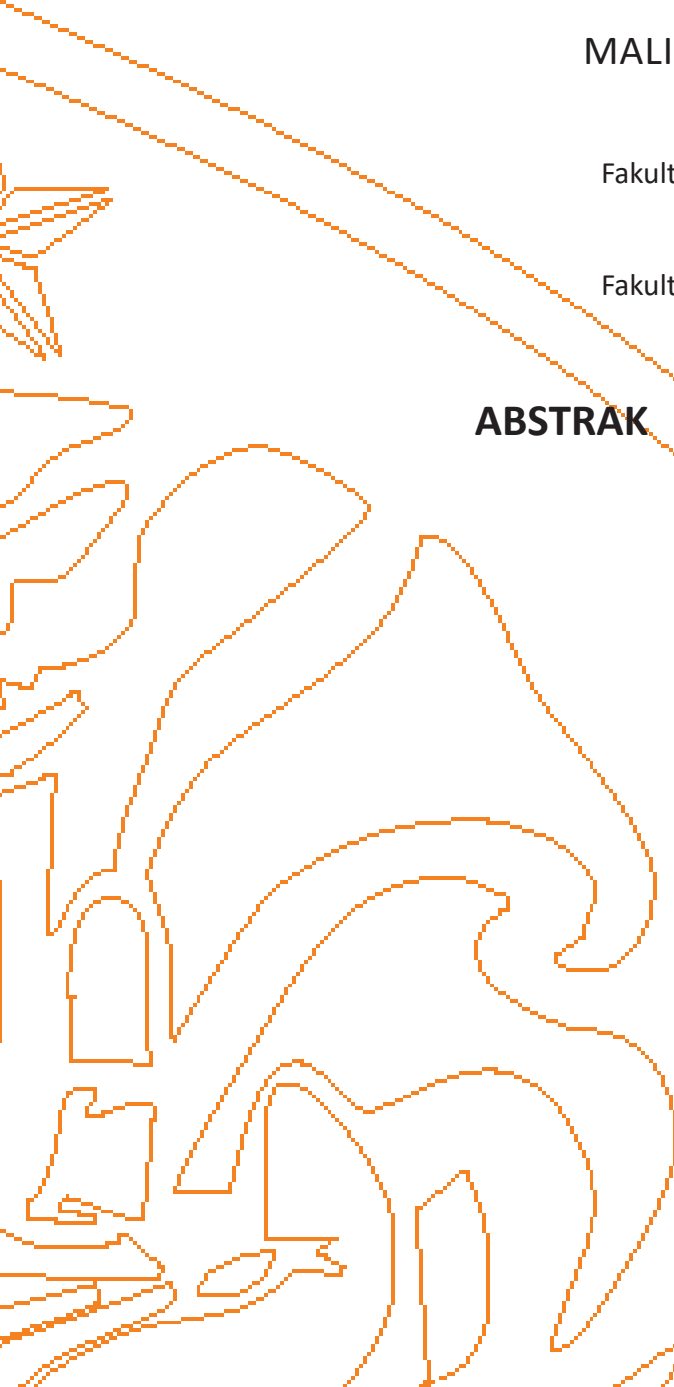

ABSTRACT

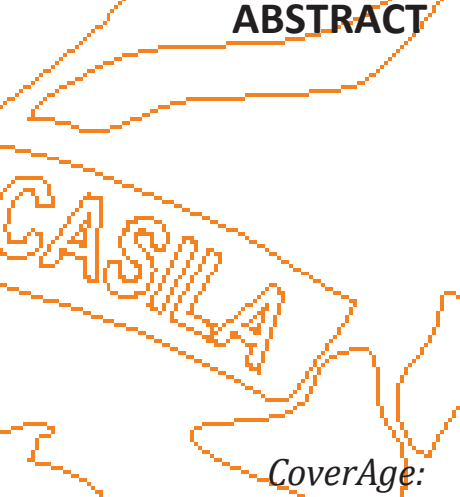

Journal of Strategic

Communication

Vol. 9, No. 1, Hal. 17-25.

September 2018

Fakultas Ilmu Komunikasi, Universitas Pancasila
Program Studi Ilmu Komunikasi ${ }^{1}$

Fakultas Komunikasi Sastra dan Bahasa, Universitas Islam '45' Bekasi Email: malikjabbar.ilkom@gmail.com

Program Studi IImu Komunikasi²

Fakultas Komunikasi Sastra dan Bahasa, Universitas Islam '45’ Bekasi Email: kr.ilkom@gmail.com
Tingkat konsumsi informasi masyarakat melalui media televisi dari berbagai generasi masih terbilang tinggi. Karakteristik yang dimiliki media televisi dengan audio-visualnya dianggap menjadi salah satu faktor utama ketertarikan masyarakat dalam memperoleh informasi. Kondisi ini membuat persaingan dalam industri media televisi terus berusaha memaksimalkan tingkat kepemirsaan mereka. Penelitian ini bertujuan untuk mengetahui strategi programming yang diterapkan Kompas TV pada program Sapa Indonesia Malam yang tayang di waktu prime time dalam meraih pemirsa. Adapun penelitian ini menggunakan metode analisis deskriptif kualitatif. Dalam merancang strategi programming untuk program Sapa Indonesia Malam, tim programming Kompas TV melakukan beberapa upaya dan menerapkan hampir sama dengan 5 elemen programming menurut Sydney. Berdasarkan hasil hasil penelitian ditemukan bahwa : (1) strategi Programming Sapa Indonesia Malam Kompas TV dimulai dengan menentukan Segmentasi dan Targetting pemirsa. Selanjutnya mengupayakan 5 elemen programming menurut Sydney dan terakhir memposisikan program kepada pemirsa (positioning). (2) Dalam menerapkan elemeh programming Sydney, program Sapa Indonesia Malam sudah hampir menerapkan seluruh elemen dengan maksimal kecuali pada elemen kelima Breadth of Appeal. (3) Program Sapa Indonesia Malam Kompas TV mampu bersaing dengan program televisi berita kompetitor yang tayang di waktu bersamaan.

Kata Kunci: Televisi, strategi programming, prime time.

The level of public information consumption through television media of various generations is still high. Characteristics of television media with audio-visual is suspected to be one of the main factors of interest of the public in obtaining information. This condition makes the competition in the television media industry continue to try to maximize their viewership. This study aims to find out the programming strategy applied by Kompas TV on the Sapa Indonesia Malam program that aired in prime time in reaching the audience. The research uses qualitative descriptive analysis method. In designing the programming strategy for Sapa Indonesia Malam program, the Kompas TV programming team made several efforts and implemented almost the same as 5 programming elements according to Sydney. Based on the results of the research, it is found that: (1) the strategy of Programming Sapa Indonesia Malam Kompas TV started by determining Segmentation and Targetting of audience. Next work on 5 programming elements by Sydney and finally position the program to the viewer (positioning). (2) In implementing the programming elements of Sydney, the Sapa Indonesia Malam program has almost applied all elements with the maximum except in the fifth element of Breadth of Appeal. (3) Sapa Indonesia Night Program Kompas TV is able to compete with competitor news television program that aired at the same time 


\section{PENDAHULUAN}

Banyaknya stasiun penyiaran berskala nasional seakan membuat persaingan yang demikian ketat pada industri media televisi. Bagi stasiun televisi komersial, rating dan share menjadi sangat penting. Peringkat atau rating dan Audience Share kerap sebagai tolak ukur untuk mendapatkan evaluasi tercepat tentang produknya.

Demikian perusahaan atau lembaga rating menyediakan jasa kepada media televisi dengan mengeluarkan laporan rutin mengenai program apa saja yang menjadi unggulan dan tidak diunggulkan lagi. Kehadiran rating di Indonesia tidak terlepas dari kehadiran televisi Swasta di Indonesia. Data rating Nielsen yang menggunakan people meter dapat mengukur prilaku menonton dengan akurat. Sejak tahun 2007 data rating Nielsen dapat disajikan perhari (Tim Peneliti AJI Jakarta, 2016: 105).

Tingginya rating dan share stasiun TV akan menentukan gengsinya di kancah pertelevisian Indonesia dan memperbesar peluang masuknya pengiklan. Hal ini tidak terlepas dari persaingan Industri media televisi. Stasiun televisi swasta bersaing ketat untuk merebut posisi teratas dalam mendapatkan jumlah penonton terbanyak, atau paling tidak masuk 5 terbesar. Sedangkan stasiun TV swasta yang baru atau yang fokus pada berita selalu berada di luar 5 besar (Tim Peneliti AJI Jakarta, 2016: 26). Persaingan pada media televisi sangat kompetitif, setiap hari posisi rating dan share stasiun bisa berubah.

Seperti Program "Sapa Indonesia Malam" Kompas TV merupakan program siaran yang disajikan setiap hari senin sampai dengan jum'at dan tayang pada pukul 19.00 - 20.00. Program berita "Sapa Indonesia Malam" selalu menyajikan berita keras atau biasa disebut Hard News dan kerap menghadirkan narasumber yang berkompeten di bidangnya. Hal itu dianggap dapat menarik perhatian lebih audiens agar dapat menyaksikan program tersebut. Sebagai contoh dalam kurun 1 bulan terakhir, terhitung sejak 12 November - 12 Desember 2017 di mana sedang maraknya informasi mengenai kasus dugaan korupsi Ketua DPR RI, Setya Novanto. Tercatat bahwa angka rata-rata rating and share program Sapa Indonesia Malam berada di angka 0,40 (rating) dan 2,02 (Share).

Dibutuhkan strategi yang kuat dalam mendongkrak angka tersebut dan menyesuaikan sasaran audien programnya, banyak peran yang terlibat dalam hal tersebut. Salah satunya adalah seorang programmer. Mengetahui pentingnya hal tersebut, maka peneliti melakukan penelitian mengenai bagaimana penerapan strategi programming Kompas TV dalam program siaran Sapa Indonesia Malam yang tayang dalam waktu utama (prime time).

\section{TINJAUAN PUSTAKA}

\section{Media Massa}

Secara sederhana Komunikasi Massa didefinisikan sebagai komunikasi melalui media massa yakni, surat kabar, majalah, radio, televisi, dan film. Salah satu definisi yang paling sederhana juga dirumuskan Bittner (1980) yang menyebutan "Mass communication is massage communicated through a mass medium to a large number of people" (Komunikasi massa adalah pesan yang dikomunikasikan melalui media massa pada sejumlah besar orang) (Morissan, 2008: 21).

\section{Media Televisi}

Televisi merupakan jaringan komunikasi dengan peran seperti komunikasi massa yaitu satu arah, menimbulkan keserempakan dan komunikan bersifat heterogen. Televisi merupakan media massa yang berfungsi sebagai alat pendidikan, penerangan, dan hiburan. Selain itu sifat negatif TV adalah sepintas lalu, tidak terlalu dapat diterima dengan sempurna, dan menghadapi publik yang heterogen (Dominick, 2000 : 192). Fungsi media televisi sama dengan fungsi media massa lainnya, yakni memberi informasi, mendidik, menghibur, dan membujuk. Tetapi fungsi menghibur lebih dominan pada media televisi. (Elvinaro, 2007: 137).

\section{Program Televisi}

Program acara yang disajikan adalah faktor yang membuat pemirsa tertarirk untuk mengikuti siaran yang dipancarkan stasiun penyiaran apakah itu radio atau televisi. Program dapat disamakan atau dianalogika dengan produk atau barang (goods) atau pelayanan (services) yang dijual kepada pihal lain, dalam hal ini pemirsa dan pemasang iklan. Dalam hal ini terdapat suatu rumusan dalam dunia penyiaran yaitu program yang baik akan mendapat pendengar atau penonton yang lebih besar, sedangan acara yang buruk tidak akan mendapatkan pendengar atau penonton (Morissan, 2008: 210-230). 


\section{Pemirsa Penyiaran Televisi}

Mengetahui secara persis apa kebutuhan pemirsa merupakan hal yang penting, tidak sekedar menghadirkan acara dengan materi atau kemasan baru tetapi isinya tetap yang lama. Pemirsa adalah pasar, dan program yang disajikan adalah produk yang ditawarkan. Strategi program siaran dalam menggapai pasar pemirsa terdiri dari serangkaian langkah yang berkesinambungan. Menurut Kottler (1980) terdiri atas tiga tahap, yaitu Segmentasi, Targetting dan Positioning. (Morissan, 2013: 174)

\section{Segmentasi Pemirsa}

Segmentasi pemirsa pada dasarnya adalah suatu strategi untuk memahami struktur pemirsa. Pengelola program penyiaran harus memilih satu atau beberapa sengmen pemirsa saja yang memiliki karakter atau respon yang sama dari seluruh penduduk indonesia (Morissan, 2013: 179). Eric Berkowitz dalam buku Morissan (2013: 178) mengatakan, jika ditinjau dari perspektif penyiaran, maka segmentasi pasar/pemirsa adalah suatu kegiaran untuk membagi-bagi atau mengelompokkan pemirsa ke dalam kotak-kotak yang lebih homogen.

\section{Target Pemirsa}

Target pemirsa adalah memilih satu atau beberapa segmen pemirsa yang akan menjadi fokus kegiatan pemasaran program dan promosi. Segmen yang dipilih dapat hanya terdiri atas satu segmen atau lebih dari satu di mana media penyiaran harus menentukan tujuan dan sasaran berdasarkan pemirsa yang sudah dipilih serta apa yang diharapkan untuk mencapai pada pemirsa tersebut. Menurut Clancy dan Shulman (1991) dalam Morissan (2013: 194), ada empat kriteria yang harus dipenuhi pengelola media penyiaran untuk mendapatkan pemirsa sasaran yang optimal. Keenpat kriteria itu adalah 1) Responsif, 2) Potensi Penjualan, 3) Pertumbuhan memadai, 4) Jangkauan Iklan.

\section{Positioning}

Positioning adalah strategi komunikasi yang berhubungan dengan bagaimana khalayak menempatkan suatu produk, merek atau perusahaan di dalam otaknya, di dalam alam khayalnya, sehingga khalayak memiliki nilai tertentu. Positioning menjadi penting bagi media penyiaran karena tingkat kompetisi yang cukup tinggi saat ini. Hiebing \& Cooper (1997) dalam Morissan (2013: 197), mendefinisikan Positioning sebagai "membangun persepsi produk di dalam pasar sasaran relatif terhadap persaingan".

\section{Strategi Programming Televisi}

Programming adalah pengorganisasian program radio atau televisi dalam periode harian, mingguan, atau periode bulanan. Programming dalam bahasa Indonesia adalah penjadwalan program yang akan diudarakan (to be aired). Jadi sinonim Programming adalah Penjadwalan (Scheduling). Lembaga penyiaran pada umumnya menggunakan strategi, yaitu secara rutin mengganti ulang penjadwalan untuk tetap merebut perhatian pendengan atau pemirsanya (Djamal dan Fachrudin, 2011: 135). Tujuan Programming bisa dianggap sebagai perangkat ringan yang digunakan untuk menarik perhatian pemirsa pada segmentasi tertentu (Junaedi,2014:168).

Tujuan programming Televisi agak berbeda dengan Radio, terutama televisi swasta dan kabel yang harus responsif pada keinginan pemasang iklan. Dengan memiliki penonton yang banyak, stasiun televisi akan mudah menjual program pada pengiklan (Junaedi, 2014: 170).

Fokus utama Programming adalah khalayak sebagai pemirsa televisi. Riset khalayak dilakukan untuk mengetahui kebutuhan dan keinginan khalayak. Sehubungan dengan selera khalayak, Sydney W. Head menguraikan lima (5) Elemen yang perlu diperhatikan dalam strategi Programming, di antaranya sebagai berikut: (Eastman \& Fergusson, 2013: 18-22) Compatibility (Kesesuaian) Program acara disusun berdasarkan kegiatan seharihari khalayak. Rutinitas khalayak seperti kapan mereka sarapan, kerja, istirahat dan sebagainya menjadi acuan televisi dalam menjalankan programming. Habit Formation (Membangun Kebiasaan) Kebiasaan Khalayak dibentuk melalui program acara yang ditayangkan. Tidak jarang dari pembentukan kebiasaan ini timbul sikap fanatik dari khalayak terhadap suatu program acara, sehingga khalayak pun enggan meninggalkan program acara tersebut. Control of Audience Flow (mengontrol aliran pemirsa) Ketika sebuah program selesai ditaangkan, maka program berikutnya disajikan. Antara program yang satu dengan berikutnya, jumlah pemirsa harus tetap dijaga. Conservation of program resources (Pemeliharaan sumber daya program) Tidak jarang program tayangan yang sangat terkenal dan digemari banyak khalayak 
menjadi sangat kuno ketika ditayangkan ke sekian kalinya. Breadth of appeal (Daya Tarik yang luas) Program acara yang ditayangkan dapat menjangkau khalayak luas, baik secara teknis maupun sosial.

\section{Pembagian Waktu Siaran}

Menentukan jadwal penayangan pada suatu acara ditentukan atas dasar perilaku pemirsa, yaitu rotasi kegiatan mereka dalam satu hari dan juga kebiasaan mereka menonton televisi atau mendengarkan radio pada jam tertentu. Aktivitas pemirsa pada umumnya memiliki pola yang sama pada setiap bagian hari, apakah pagi, siang atau malam hari. Programmer menyusun jadwal program acara berdasarkan aktivitas pemirsa ini. Secara umum Programmer membagi siaran menjadi beberapa bagian: (Head, Sterling, 1982: 217) dalam buku Morissan (2008:344). Prime time (Jam 19.30-23.00), Late Fringe Time (Jam 23.00-01.00), All Others Time (Jam 01.00-10.00), Day Time (Jam 10.00-16.30), Fringe Time (Jam 16.30-19.30). Tetapi pola pembagian waktu siara ntersebut berbeda pada saat akhir pekan (Sabtu dan Minggu). Other Time untuk akhir pekan dimulai dari pukul 01.0007.00 atau berakhir lebih cepat 3 jam dibandingkan hari biasa. Ini menunjukkan bahwa pemirsa cukup banyak menonton televisi pada pagi hari di hari Sabtu dan Minggu (Morissan, 2008: 344).

\section{METODE}

Metode yang digunakan dalam penelitian ini yaitu metode kualitatif deskriptif. Adapun key informan yakni Helmi Ananto Nugroho selaku Kepala Departement Research and Data Mining Kompas TV. Sedangkan, informan penelitian ini di antaranya Didi Istiadi selaku Manager Departement Planning and Schedulling, dan Susanto selaku Content Analist di Departement Research and Data Mining. Alasan memilih keduanya sebagai informan adalah untuk mendukung informasi bagaimana jalannya skema Programming yang dilakukan di dalam Kompas TV khususnya pada program Sapa Indonesia Malam.

Dalam penelitian kualitatif, pengumpulan data terbagi menjadi dua, yaitu data primer dan data skunder. Data primer dalam penelitian ini yaitu : Pertama dengan cara Pengamatan peneliti akan melakukan pengamatan ke Departemen Programming di Kompas TV, khususnya ke Divisi Research and data mining oleh Helmi Ananto Nugroho dan Divisi Planning and Scheduling oleh Didi Istiadi. Kedua ialah wawancara secara mendalam kepada informan. Data Sekunder berupa buku-buku, data dari dokumen yang berupa catatan formal, jurnal, artikel dan sebagainya.

\section{HASIL DAN PEMBAHASAN}

\section{Pemirsa Penyiaran Televisi}

\section{Segmentasi}

Secara demografis, Segmentasi Kompas TV secara umum menurut Helmi melalui wawancara dengan penulis mengatakan bahwa Kompas TV telah membidik Segmentasi pemirsanya dengan lebih fokus yaitu pemirsa dengan kategori Usia 15 tahun atau lebih. Sehingga bila disaksikan memang siaran Kompas TV tidak bermain dengan Cartoon dan program anak. Selain itu, mereka juga mengkategorikan jenis pemirsanya berdasarkan strata Sosial dan Ekonomi (SEC). Adapun pengkategorian tersebut di antaranya diukur berdasarkan rata-rata pendapatan, penggunaan jenis air mineral dan penggunaan tabung gas dalam keluarga seperti pada gambar 4.5 sebelumnya. Tabel tersebut menjadi bahan acuan Kompas TV dalam menentukan segmen pemirsanya. Adapun segmen yang disasar Kompas TV secara langsung diungkapkan Helmi adalah Upper, dan lebih ditegaskan lagi terhadap kelas Upper satu dan Upper dua. Pada tabel 2 mengenai tabel SEC tersebut terbagi menjadi 5 kelas yaitu Upper 1, Upper 2, Middle 1 Middle 2 dan Lower.

Melalui pernyataan Helmi saat wawancara dengan penulis menegaskan bahwa segmentasi Kompas TV lebih menengah ke atas atau biasa tim Programming mereka menyebutnya Upper (Upper 1 dan Upper 2). Dalam wawancara Penulis dengan Helmi juga terdapat satu pernyataan yang isinya mengatakan bahwa sampai saat ini dominasi pemirsa Kompas TV secara umum belum tercapai. Karena menurutnya Kompas TV di brand dengan penonton berita atau News. Tetapi menurutnya pada kenyataan dalam kurun satu tahun terakhir di 2017 dominasi usia adalah 30 tahun lebih.

Di sisi lain, segmentasi pemirsa dari segi Geografis Kompas TV dinyatakan kembali oleh Helmi, bahwa untuk saat ini Kompas TV lebih memfokuskan pemirsa yang berlokasi di Pulau 
Jawa. Menurutnya karena riset Nielsen sendiri sampai saat ini juga masih dan baru tersebar di 11 Kota Indonesia saja. Terlebih memang alasan tersebut lebih mengarah ke pandangan bisnis. Riset Nielsen sendiri menurut Helmi, $60 \%$ dari sampelnya itu berada di Jakarta dan sekitarnya, jadi bilamana mengikuti kemauan di luar Jakarta, secara keseluruhan tidak akan dapat banyak.

\section{Targetting}

Potensi pemirsa program Sapa Indonesia Malam sebagai program harian potensi pemirsanya ialah usia 30 atau lebih dan segi Sosial dan Ekonomi pemirsanya di level Upper. Bila sandingkan dengan segmentasi yang dituju sebelumnya bahwa program tersebut belum mampu menyasar Usia 15 sampai 29 tahun.
Seperti contoh profil pemirsa Sapa Indonesia Malam pada tabel 1. bawah ini :

Pada gambar tabel 1. merupakan profil pemirsa Sapa Indonesia Malam yang diperoleh penulis setelah melakukan perizinan ke pihak Kompas TV untuk memaparkan data. Di tabel 1. merupakan hasil capaian pemirsa Sapa Indonesia Malam pada tanggal 13 November sampai dengan 12 Desember 2017 atau periode satu bulan. Data tersebut juga memberi gambaran terkait segmentasi dan target pemirsa yang telah dicapai dalam periode tersebut. Bila diperhatikan dalam kurun satu bulan tersebut, memang terlihat dominasi Usia pemirsa (diberi tanda kuning) bila diklasifikasikan berdasarkan pada tabel 1. berada di antara usia 30-39, usia 40-49 dan usia 50 lebih. Hal tersebut selaras dengan

Tabel 1.

\section{Profil Pemirsa Sapa Indonesia Malam}

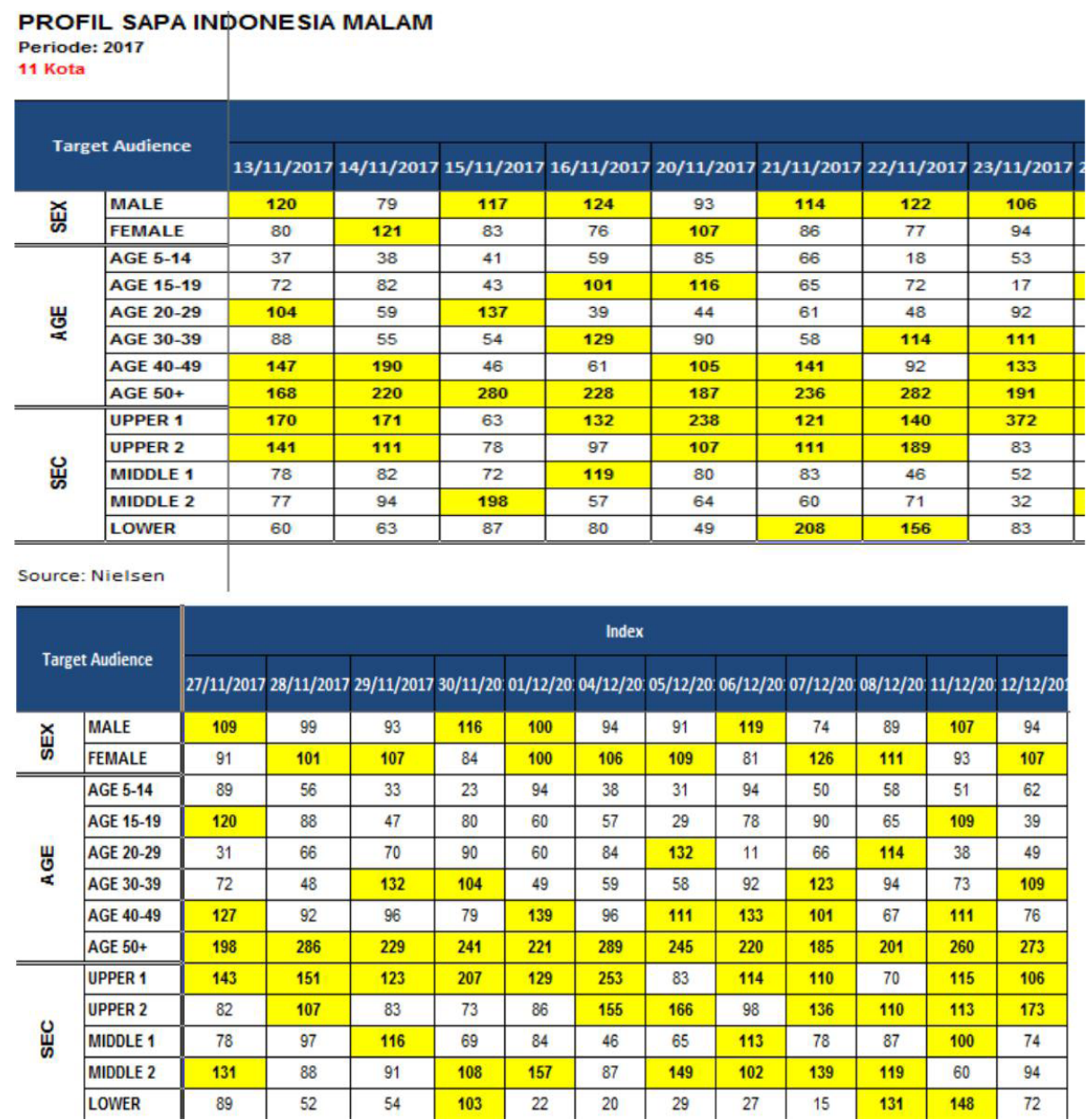


pernyataan Helmi yang mengungkap bahwa dalam kurun satu tahun terakhir, Segmentasi berdasarkan usia yang mendominasi Kompas TV secara umum adalah Usia 30 dan selebihnya. Potensi capaian pemirsa Sapa Indonesia Malam berdasarkan table 1. memang sesuai dengan ungkapan Helmi, bahwa dominasi pemirsa Kompas TV adalah pemirsa News dengan kategori usia di atas 30 tahun.

Begitu pula dengan Targetting dari segi Sosial dan Ekonomi pemirsa (SEC) program Sapa Indonesia Malam, jika berdasarkan klasifikasi pemirsa yang dijelaskan sebelumnya dan memperhatikan tabel 1. di atas memang terlihat kesesuaian. Di mana target pemirsa program Sapa Indonesia Malam adalah sama dengan target pemirsa Kompas TV secara general, maka terlihat jelas dominasi pemirsa level Upper 1 dan Upper 2 seperti pada tabel 1. yang menandakan dominasi pemirsa Sapa Indonesia Malam.

\section{Positioning}

Dalam upaya membangun positioning di sebuah program kepada pemirsanya tentu perlu dilakukan upaya-upaya untuk membangun citra sebuah program. Program siaran Sapa Indonesia Malam merupakan salah satu produk siaran Kompas TV yang dianggap perlu dibangun citra programnya kepada masyarakat. Selain programnya yang tayang pada waktu prime time dengan tingkat persaingan yang tinggi, program tersebut juga dianggap salah satu dari tiga program yang akan mewakilkan pemirsa Kompas TV secara umum.

Program Sapa Indonesia Malam yang baru hadir di bulan Juli 2017, memerlukan penguatan merek program kepada masyarakat. Dan beberapa upaya telah dilakukan pengelola program untuk membangun citra merek pada program tersebut seperti ungkapan Susanto selaku Content Analyst Kompas TV, melalui wawancara dengan penulis mengatakan bahwa identitas program Sapa Indonesia Malam adalah konsistensi terhadap tema politik.

\section{Strategi Programming Kompas TV}

\section{Compatibility (Kesesuaian)}

Program acara disusun berdasarkan kegiatan sehari-hari khalayak. Rutinitas khalayak seperti kapan mereka sarapan, kerja, istirahat dan sebagainya menjadi acuan televisi dalam menjalankan programming. Namun, hal tersebut sedikit berbeda dengan yang disampaikan Helmi mengenai kesesuaian pemirsa. Di mana menurutnya televisi berita tidak bisa disamakan dengan televisi Genaral Entertainment. Di mana menurutnya Kompas TV itu target pemirsanya lebih khusus dan tidak bisa sembarangan menempatkan program di prime time week days dan tidak bisa juga menempatkan program yang sangat entertainment pada slot tersebut, karena penonton loyal program news juga ada pada waktu tersebut. Dalam pengklasifikasian pemirsa, Helmi juga mengatakan bahwa di Kompas TV mengacu berdasarkan SEC (Social, Economy Clasfication) yang terbagi menjadi lima kategori yang di antaranya Upper 1, Upper 2, Middle 1, Middle 2 dan Lower.

Tabel 2.

Segmentasi Economy Clasification

\begin{tabular}{|c|c|}
\hline \multirow{4}{*}{$\begin{array}{c}\text { SOCIAL ECONOMY } \\
\text { CLASIFICATION } \\
\text { (SEC) }\end{array}$} & UPPER 1 \\
\cline { 2 - 2 } & UPPER 2 \\
\cline { 2 - 2 } & MIDDLE 1 \\
\cline { 2 - 2 } & MIDDLE 2 \\
\hline
\end{tabular}

Sumber : Helmi Ananto Nugroho, Kompas TV

Sebagaimana tabel 2. yang menjadi acuan Kompas TV dalam menentukan sasaran arah pemirsanya. Program Sapa Indonesia Malam yang menurut Helmi memiliki sasaran di 2 kategori yakni Upper 1 \& Upper 2, maka sasaran spesifik dituju adalah Upper. Dengan rentang usia 30 tahun ke atas. Menurut Helmi, kalo berbicara program berita di Kompas TV potensinya tidak jauh berbeda seperti tadi.

Karena itu menjadi satu hal penting melakukan riset kepemirsaan di sebuah perusahaan media, khususnya televisi untuk mengetahui aktivitas pemirsanya. Pada program Sapa Indonesia Malam ini yang memang dikhususkan pada segmentasi usia Dewasa (Usia 30+) memiliki aktifitas padat dan mengambil waktu luang menyaksikan televisi setelah pulang kerja untuk memenuhi kebutuhan informasinya, maka disajikanlah program tersebut. Dengan begitu penerapan elemen strategi kesesuaian pada pemirsa Kompas TV pada program Sapa Indonesia Malam berjalan dengan maksimal. Terlebih menurut Helmi, setelah di tracking dalam kurun 6 bulan terakhir di mana dominasi 
pemirsa yang paling besar adalah rentang Usia 35 sampai dengan 50 tahun dengan dominasi SEC Upper 1 dan Upper 2 yang paling besar.

\section{Habit Formation (Membangun Kebiasaan)}

Kebiasaan khalayak dapat dibentuk melalui program acara yang ditayangkan, baik program acara harian ataupun mingguan. Tidak jarang dari pembentukan kebiasaan ini timbul sikap fanatik dari khalayak terhadap suatu program acara, sehingga khalayak pun enggan meninggalkan program acara tersebut. Misalnya Program Siaran Sapa Indonesia Malam yang tayang pukul 19.00 sampai dengan $20.00 \mathrm{WIB}$, ada potensi pemirsa setelah beberapa kali menyaksikan program Sapa Indonesia Malam dan merasa suka atau cocok dengan sajian program maka besar kemungkinan akan kembali menyaksikan keesokan hari.

Salah satu upaya yang diungkapan Didi Istiadi saat wawancara dengan penulis, mengatakan bahwa secara internal dalam menghadapi persaingan program kompetitor di slot waktu yang sama pada saat disiarkan Sapa Indonesia Malam ialah dengan cara menyajikan program seperti apa yang disajikan kompetitor, cara ini biasa disebut istilah Head to Head.

Upaya lain yang diterapkan pada Program Sapa Indonesia Malam Kompas TV dalam membangun kebiasaan pemirsa adalah dengan menyajikan konten Kompas Interaktif. Kompas Interaktif yang seakan membuat pemirsa berinteraksi dengan program Sapa Indonesia Malam, bahkan dengan si pembawa acara. Konten Kompas Interaktif ini memiliki 2 jenis, pertama adalah polling interaktif dan kedua adalah komentar interaktif. Dalam satu segmen pembahasan biasanya akan dimunculkan pertanyaan interaktif ataupun opsi dari polling interaktif yang dapat pemirsa pilih secara terbuka.

\section{Control of Audience Flow (Mengontrol Aliran Pemirsa)}

Hal itu diakui oleh Didi Istiadi, selaku Kepala Departement Planning and Schedulling Kompas TV. Didi mengatakan bahwa pemirsa televisi di Indonesia tidak loyal, karena ketika peforma program A misalnya dalam kurun 1 bulan peformanya bagus kemudian tiba-tiba di satu hari peforma program tersebut bisa saja tiba-tiba menjadi buruk. Tentu saja kejadian tersebut tidak bisa disalahkan kepada pemirsa, karena pemirsa memiliki kebebasan dalam menyaksikan program.

Kebebasan pemirsa dalam mengonsumsi informasi memang sangat luwes dan tanpa paksaan. Susanto selaku Content Analyst juga menambahkan bahwa aliran Pemirsa pada Program Sapa Indonesia Malam fluktuatif atau tidak stabil, jadi terkadang bagus ataupun buruk.

Terkait pernyataan Didi Istiadi mengenai pemirsa televisi yang tidak loyal, ia juga menambahkan bahwa teknisnya terjadi karena hal biasa, pemirsa dengan mudah berpindah stasiun televisi karena program yang disaksikan sedang iklan atau Comersial break. Namun, setelah program kembali disiarkan belum tentu akan kembali menyaksikan program sebelumnya karena sudah tertarik dengan program di televisi lain.

4. Conservation of Program Resources (Pemeliharaan Sumber Daya Program)

Pemeliharaan sumber daya program menjadi hal penting dalam upaya mempertahanan dan meraih pemirsa semaksimal mungkin. Program Sapa Indonesia Malam Kompas TV yang tayang di slot prime time turut mempertimbangkan elemen pemeliharaan sumber daya program. Apalagi mengingat program televisi kompetitor (TV One) di slot bersamaan juga menyajikan program sejenis Sapa Indonesia Malam Kompas TV.

Program Sapa Indonesia Malam memiliki durasi waktu 60 menit untuk tampil di slot prime time. Menurut Susanto, karakteristik Sapa Indonesia Malam ialah konsisten dengan membahas tema-tema politik. Tema Sapa Indonesia Malam selalu membahas dan mengulas mengenai suatu isu politik yang kerap diperbincangkan publik.

Siaran program pada televisi dilakukan terus menerus sepanjang hari, karena itu diperlukan ketersediaan materi/bahan dan sumber daya lainnya yang mendukung program harus diperhitungkan dengan baik. Begitu pula Program Sapa Indonesia Malam yang tayang setiap Senin sampai Jumat dalam satu pekan tentu diperlukan pemeliharaan materi ataupun tema yang dipersiapkan dan diperhitungkan untuk setiap tayang edisinya. 


\section{Breadth of Appeal (Daya Tarik Luas)}

Adapun akan dipaparkan data mengenai angka kepemirsaan yang diperoleh program Sapa Indonesia Malam di beberapa kota yang menjadi sampel Lembaga Riset Nielsen Indonesia, sebagai berikut :
Berdasarkan data pada Tabel 3. terdapat data yang mengenai daya jangkau pemirsa atau pemirsa pada siaran di Kompas TV pada Program Sapa Indonesia Malam edisi 27 November sampai 1 Desember 2017. Data mengenai angka kepemirsaan program Sapa Indonesia Malam dalam kurun waktu satu

Tabel 3.

Angka Kepemirsaan Sapa Indonesia Malam

\begin{tabular}{|c|c|c|c|c|c|c|c|c|c|c|c|c|c|}
\hline \multirow{2}{*}{\multicolumn{2}{|c|}{$\begin{array}{l}\text { ISO Week } \\
\text { ISO Week }\end{array}$}} & \multicolumn{2}{|c|}{ Jakarta } & \multicolumn{2}{|c|}{ Surabaya } & \multicolumn{2}{|c|}{ Yogyakarta } & \multicolumn{2}{|c|}{ Bandung } & \multicolumn{2}{|l|}{ Medan } & \multicolumn{2}{|c|}{ Semarang } \\
\hline & & TVR & Shal & TVR & Sha & e TVR & Share & \begin{tabular}{|l|l|} 
TVR \\
\end{tabular} & Share & TVR & Share & TVR & Share \\
\hline \multicolumn{2}{|c|}{$27 / 11 / 2017$} & 0,08 & 02 & & 0 & $1,7 \mathrm{~s}$ & 9,32 & \begin{tabular}{l|l}
2 & 1,13 \\
\end{tabular} & 4,63 & 0,00 & 0,00 & & 0,54 \\
\hline \multicolumn{2}{|c|}{$28 / 11 / 2017$} & 0,29 & 1,5 & & & $3,0 t$ & \begin{tabular}{l|l}
6 & 19,68 \\
\end{tabular} & 0,24 & 1,03 & 0,00 & 00 & &, 41 \\
\hline \multicolumn{2}{|c|}{$29 / 11 / 2017$} & 0,15 & 0,7 & & 2 & \begin{tabular}{l|l}
4 & 0,60 \\
\end{tabular} & 3,92 & 1,36 & 4,78 & 0,00 & 0,00 & to & 14 \\
\hline \multicolumn{2}{|c|}{$30 / 11 / 2017$} & 0,32 & 1,5 & & 9 & 2,72 & \begin{tabular}{|l|l|}
2 & 23,55 \\
\end{tabular} & \begin{tabular}{l|l}
5 & 0,27 \\
\end{tabular} & 1,24 & 0,00 & 0,00 & 0, &, 63 \\
\hline \multicolumn{2}{|c|}{$01 / 12 / 2017$} & 0,31 & 1,5 & & 1 , & \begin{tabular}{l|l}
9 & 1,00 \\
\end{tabular} & \begin{tabular}{l|l}
0 & 4,42 \\
\end{tabular} & 0,48 & 1,74 & 0,00 & 0,00 & $0,($ & 0,10 \\
\hline \multicolumn{2}{|c|}{ Makassar } & \multicolumn{3}{|c|}{ Denpasar } & \multicolumn{2}{|c|}{ Banjarmasin } & Salemb: & ang & \multicolumn{2}{|c|}{ surakarta } & [TVI & \multirow{2}{*}{\multicolumn{2}{|c|}{ [Share] }} \\
\hline VR & Share & TVF & & hare & VR & \begin{tabular}{l|l} 
Share & T
\end{tabular} & \begin{tabular}{l|l} 
VR & $s$
\end{tabular} & Share & TVR & Share & & & \\
\hline 0,01 & 0,07 & & 11 & 9,57 & 0,16 & 0,48 & 0,46 & 1,70 & 0,18 & 0,85 & & 0,31 & 1,6 \\
\hline 0,01 & 0,03 & & 43 & 2,80 & 0,04 & 0,14 & 0,13 & 0,46 & $1, f$ & 7,00 & & 0,30 & 1, \\
\hline 0,61 & 3,85 & & 0,62 & 3,44 & 0,03 & \begin{tabular}{|c|}
0,17 \\
\end{tabular} & 0,08 & 0,27 & 0,16 & 0,64 & & 0,27 & 1,30 \\
\hline 0,10 & 0,41 & & 1,64 & 9,35 & 0,42 & 1,12 & 0,04 & 0,14 & 0,14 & 0,52 & & 0,36 & 1,81 \\
\hline 0,41 & 2,44 & & 0,73 & 4,92 & 0,03 & 0,20 & \begin{tabular}{l|l}
0,16 \\
\end{tabular} & 0,75 & 0,70 & 6,37 & & 0,33 & 1,64 \\
\hline
\end{tabular}

Sumber : Research and Data Mining Kompas TV

pekan terlihat dominasi pemirsa terdapat di lima kota besar seperti Bandung, Denpasar, Surabaya, Yogyakarta dan Jakarta. Selaku Kepala Departement Research and Data Mining Kompas TV, Helmi mengungkap terkait daya tarik pemirsa yang memang lebih memfokuskan kepada pemirsa di Pulau Jawa. Karena menurutnya sampel pemirsa dari Nielsen memang hanya di 11 kota dan jika di ulas secara rinci perkota, sampel di Jakarta mencapai $60 \%$ dari populasi.

Elemen keberhasilan programming mengenai Daya Tarik Luas yang sudah ditanggapi oleh Helmi dapat dikaitan dengan tema pembahasan yang mendominasi terkait isu politik yang hangat diperbincangkan di Pulau Jawa dan terpusat pada pemberitaan di Jakarta dan sekitarnya.

Secara Geografis diambil data menggunakan sampel Nielsen yang menjangkau 11 Kota di Indonesia bahwa Sapa Indonesia Malam terlihat mendominasi pemirsanya di wilayah Pulau Jawa.
Hal tersebut sesuai dengan ungkapan Helmi mengenai jangkau pemirsa Kompas TV yang menurutnya masih fokus membidik di Pulau Jawa. Alasan mendasarnya mengungkap bahwa lebih ke mungkin ke pandangan bisnis, karena sampel Nielsen bahkan mencapai angka $60 \%$ di Jakarta. Maka tidak heran bila tema dan materi pembahasan dalam tiap program Sapa Indonesia Malam Kompas TV lebih mengutamakan isu politik di Jakarta, seperti pada hasil penelitian penulis yang dipaparkan sebelumnya. Hal ini juga berkaitan dengan pembahasan mengenai segmentasi dan targetting pemirsa di Kompas TV.

Lima elemen programming Sydney memang banyak diterapkan oleh berbagai media dalam menghadapi persaingan dan memaksimalkan peforma setiap programnya. Namun dalam menentukan pemirsa dalam sebuah stasiun televisi ataupun pada sebuah program siaran diperlukan pengkategorisasian pemirsanya agar dapat membidik calon pemirsanya dengan jelas. Dalam hal ini strategi programming dalam menggapai 
pasar pemirsa terdiri dari serangkaian langkah yang berkesinambungan. Menurut Kottler dalam buku Morissan: Manajemen Media Penyiaran terdapat tiga kategori dalam dalam menetapkan pemirsa, yaitu Segmentasi, Targetting dan Positioning.

Langkah strategis tim Programming Kompas TV setelah menentukan segmentasi dan targetting pemirsa, kemudian upaya penerapan lima elemen programming Sydney adalah hal lain yang perlu diperhatikan adalah positioning. Dalam upaya membangun positioning di sebuah program kepada pemirsanya tentu perlu dilakukan upayaupaya untuk membangun citra sebuah program. Salah satu upaya yang dilakukan Kompas TV dalam membangun positioning program Sapa Indonesia Malam adalah dengan menempatkan waktu siaran program Sapa Indonesia Malam di slot prime time. Upaya tersebut merupakan langkah tepat dalam membangun citra program Sapa Indonesia Malam yang termasuk program baru. Karena Positioning menjadi salah satu hal penting yang perlu diperhatikan dalam merancang strategi guna menghadapi persaingan industri media.

Menurut ungkapan Susanto mengenai identitas program Sapa Indonesia Malam juga dapat dianggap sebagai salah satu upaya memposisikan program Sapa Indonesia Malam di penilaian pemirsa. Menurutnya program Sapa Indonesia Malam identik dan konsisten dengan tema-tema politik yang selalu diulas, jika dibandingkan dengan program lain yang sejenis namun materi atau tema pembahasan cenderung tidak konsisten. Penulis juga memperhatikan catatan harian program Sapa Indonesia Malam pada periode bulan November dan Desember 2017, jika dicermati memang dari berbagai edisi yang tayang setiap hari Senin sampai dengan Jum "at tema program tersebut cenderung identik dengan tema dan pembahasan politik.

\section{SIMPULAN}

Berdasarkan penelitian yang telah dilakukan, maka peneliti menyimpulkan bahwa dalam merancang strategi, tim programming di Kompas TV dengan maksimal menerapkan strategi programming yang menurut Sydney W Head yang terdiri atas lima elemen. Kelima elemen tersebut di antaranya Kesesuaian, Membangun Kebiasaan, Mengontrol Aliran Audiens, Pemeliharaan Sumber Daya Program dan Daya Tarik Luas. Berdasarkan hasil dan pembahasan penulis, Kompas TV telah menerapkan empat dari lima elemen tersebut.
Satu elemen yang kurang dimaksimalkan oleh programming Kompas TV di program Sapa Indonesia Malam adalah elemen daya tarik luas. Dan sebelum disiarkan program Sapa Indonesia Malam, tim Programming Kompas TV telah melakukan riset dan menganalisa mengenai prilaku dan ketersediaan pemirsa pada slot waktu yang akan disiarkan untuk Sapa Indonesia Malam.

\section{DAFTAR PUSTAKA}

Dominick, J. R. (2000). The Dynamics of mass. New York: Random House

Dewi, I. T. (2014). Strategi programming MNC TV dalam mempertahankan program Dakwah. Tangeran : Universitas Islam Negeri Jakarta.

Elvinaro, A, dkk. (2007). Komunikasi Massa Suatu Pengantar:Edisi Revisi. Jakarta: Simbiosa Rekatama Media.

Eastman, S, Fergusson, D. (2013). Media Programming "Strategies and Practices" Ninth Edition. Boston : Wadsworth.

Junaedi, F. (2014). Manajemen Media Massa: Teori, Aplikasi dan Riset. Yogyakarta: Buku Litera.

Laras Ayu, N. (2016). Analisis Manajemen Strategis Program Berita Indonesia Malam Lembaga Penyiaran Publik TVRI. Bandung : Universitas Telkom.

Morissan. (2008). Manajemen Media Penyiaran : Strategi Mengelola Radio \& Televisi. Jakarta. Kencana.

Tim Peneliti Aji. (2016). Mendorong Akuntabilitas Rating Media Penyiaran. Jakarta: Tifa. 